\title{
The Social Safety Net: An Alternative to Rawls's Two Principles of Justice1
}

\section{J. Winston Chiong \\ School of Medicine \\ University of California, San Francisco}

In A Theory of Justice, John Rawls argues for a view which he entitles "justice as fairness," according to which the principles of a just social organization are those which would be chosen by the members of society in an original position of fairness. Rawls's framing of this original position has had a great intuitive appeal, perhaps because it incorporates the ideals of rationality and impartiality that are central to our everyday understanding of justice. However, the principles which Rawls derives from this startingpoint appear to depart radically from many commonly held and intuitive beliefs about justice and the aims of social organizations. While I find Rawls's conception of the original position to be uniquely compelling, I believe that there is something to be said for a somewhat more conservative conception of justice. Rawls himself acknowledges the possible independence of the original position from the substantive principles which he endorses, pointing out that

justice as fairness, like other contract views, consists of two parts: (1) an interpretation of the initial situation and of the problem of choice posed there, and (2) a set of principles which, it is argued, would be agreed to. One may accept the first part of the theory (or some variant thereof), but not the other, and conversely. [p. 15]

\footnotetext{
1 I would like to lake this opportunity to acknowledge the helpful comments and advice of Christopher Kulp, Samucl Scheffler, Jason Bridges, Ina Roy, and Maria Merrilt, at various stages in the development of this paper. I would also like to thank Stephen Menicucci and the Santa Clara University Undergraduate Philosophy Conference for the opportunity to present an earlier version of this paper, and the editors and reviewers of Auslegung for their inpul and suggestions.
} 
In this paper, I hope to use the original position to advocate a conception of justice which is somewhat less egalitarian than the one which Rawls develops. Central to this task will be the claim that parties in the original position would indeed prefer this conception of justice to Rawls's own.

\section{Prima Facie Objections to Rawls's Principles of Justice}

Before proceeding with arguments from the original position, I would like to bring up a few pre-philosophical objections to Rawls's principles. Let us consider Rawls's two principles of justice as formulated at the end of section 13 under the interpretation of "Democratic Equality."

1. Each person is to have an equal right to the most extensive basic liberty compatible with a similar liberty for others. [p. 60]

2. Social and economic inequalities are to be arranged so that they are both (a) to the greatest benefit of the least advantaged [the difference principle] and (b) attached to offices and positions open to all under conditions of fair equality of opportunity. [p. 83]

Rawls writes that these principles have a lexical structure-the first principle must be satisfied before we can take steps to satisfy the second principle. This ordering also requires that any steps taken to satisfy the second principle must be in accordance with the first principle.

The first principle of equal liberty and the requirement in 2(b) of fair equality of opportunity should be familiar and persuasive to most citizens of contemporary constitutional democracies. However, the difference principle of 2(a) marks Rawls's departure from the mainstream of contemporary political discourse. What I would like to call attention to, in particular, is Rawls's insistence on the injustice of certain kinds of inequality. For instance, on page 
62 he observes that his specific principles represent a more general conception of justice which includes the idea that, "Injustice, then, is simply inequalities that are not to the benefit of all." Rawls claims a classical inspiration for this account in Aristotle's sense of justice as refraining from pleonexia; nonetheless, I submit that this is a highly unconventional view of injustice.

For instance, in our own society, there are great economic inequalities, such that some have much more than they require to support themselves and their families, while many others live in poverty, without access to employment, proper nutrition, or adequate medical care. There are a number of reasons why one might find this situation unsatisfactory. On a Rawlsian account this system is unjust, presumably because these inequalities are not to the benefit of the least advantaged. However, I would like to argue that what disturbs us about this situation is not the presence of inequalities per se; instead it is the presence of poverty in a society which is prosperous enough to provide a decent standard of living for all of its members. What arouses our sense of injustice, then, is not simply that there are inequalities; but rather that these inequalities result in unnecessary want and suffering which could be avoided through a more humane economic and political system.

Or imagine a society in which everyone's basic material needs are satisfied, and in which there are a few lucky individuals who enjoy a greater share of wealth than do the others. This would be a society with inequalities which presumably are not all to the benefit of the least advantaged, but in which these inequalities do not result in unnecessary deprivation. Compare this society with another society, in which everyone's basic material needs are satisfied and no one enjoys any wealth above this basic standard of living. There may be reasons to prefer one society over the other: one might suggest that the second society will enjoy a more democratic spirit, while another might say that the first society is more conducive to the pursuit of beautiful art and literature. However, I am not certain that justice demands that we prefer the second society to the first, as Rawls's emphasis on inequality appears to require. Even if surpluses are inequalities which benefit only their possessors and which are assigned in a morally arbitrary manner, it seems almost spiteful to insist that no one ought to enjoy them. 


\section{The Social Safety Net and the Original Position}

With these objections in mind, I would like to advocate an alternative conception of justice, which $I$ take to be based on a more moderate idea: that of the "social safety net." I interpret this as involving the idea that there is a basic minimum of material goods that individuals require to lead satisfactory lives, and as stating that just social institutions should guarantee this minimum, within reason, to those who abide by those institutions. In situations in which it is not possible to guarantee this minimum standard to all, I believe that this ideal would require a society to provide this standard of living to as many of its members as possible. Such a conception of justice might be formulated with the following lexical structure:

1'. Each person is to have an equal right to the most extensive basic liberty compatible with a similar liberty for others.

2'. When possible, each person is to have reasonable access to a satisfactory minimum material standard of living,

OR

When this is not possible, as many people as is possible are to have reasonable access to a satisfactory minimum material standard of living.

3'. After 1' and 2' are satisfied, social and economic inequalities are to be allowed so long as these inequalities are attached to offices and positions open to all under conditions of fair equality of opportunity.

In order to argue for this conception, it is necessary to demonstrate that these principles would be chosen by individuals 
in the original position of fairness. Let us review the basic features of this original position. As Rawls writes, the guiding idea of justice as fairness is

that the principles of justice for the basic structure of society are the object of the original agreement. They are the principles that free and rational persons concerned to further their own interests would accept in an original position of equality as defining the fundamental terms of their association. [p. 11]

Perhaps the most controversial element in Rawls's conception of the original position is the stipulation that the principles of justice be chosen by parties behind a "veil of ignorance." Parties in the original position are (or must imagine themselves to be) unaware of particular individual facts such as their place in society, their fortune in the distribution of natural assets and abilities, their conception of the good, and the special features of their respective individual psychologies (such as their aversion to risk or their tendency to pessimism or optimism). These restrictions on their knowledge are necessary, Rawls argues, to ensure that no one can tailor the principles of justice to suit his or her own personal circumstances, and also to ensure that no one is advantaged or disadvantaged by fortune or social circumstances in his or her choice of principles. Furthermore, the parties in the original position are unaware of the particular circumstances of their own society: its political or economic situation, its level of civilization and culture, and to which generation in a society they belong. This is because issues of justice can arise between generations just as they can arise between individuals; and also because, at least on the Kantian interpretation developed in $\S 40$, the choice of principles should be independent of contingencies such as the level of societal progress or economic abundance. More mundanely, one might point out that the principles of justice should hold regardless of current social or economic circumstances.

So what do the parties in the original position know? According to Rawls, there are no limits to general information: they have access 
to political and economic theory and the laws of human psychology, and an understanding of the basis of social organization. More than that, they know that they live under the "circumstances of justice," the conditions under which human cooperation is both possible and necessary. I assume the circumstances of justice to include the fact that people require some basic minimum of material goods in order to lead satisfactory existences-without this assumption, the parties could not make sense of the principles which I have endorsed.

The parties in the original position would consider, among other factors, the different life expectations available to different representative individuals under these two competing conceptions of justice. Let us examine three general circumstances: societies in which there are not enough resources to guarantee a satisfactory life for all, societies in which there are just enough resources to guarantee a satisfactory life for all, and societies in which there are more than enough resources to guarantee a satisfactory life for all. To do so, I will attempt to diagram the life expectations available to each representative individual in a society. The following is a diagram of a society which does not have enough resources to provide all of its members a satisfactory standard of living. (The worst-off representative individual is on the left-most side-moving rightward I diagram gradually better-off individuals until, at the far right, we have the most favored representative individual in the society.) The dotted line represents a minimum satisfactory material standard of living.

\section{Diagram 1: Insufficient resources}
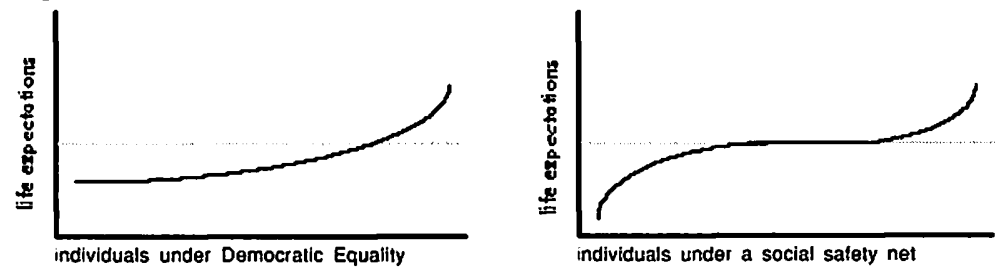

Under conditions of insufficient resources, the position of the worst-off is higher under Democratic Equality than under the social safety net. However, the social safety net does have a lower 
boundary, provided by the principle of equal liberty - the worstoff are not to be exploited, and slavery (which, it has been argued, would be permitted by utilitarianism) is prohibited. Also, as would be expected, there are more individuals at or above a satisfactory standard of living under the social safety net than under Democratic Equality. While Rawls's principles would be favored by the worstoff, the social safety net would be favored by those in the middle.

\section{Diagram 2: Sufficient resources}
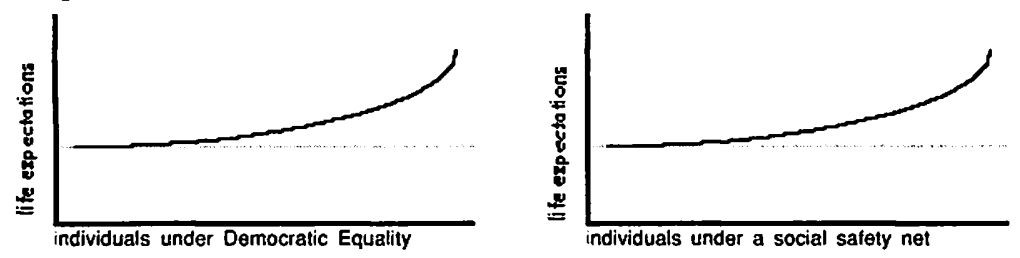

Under conditions in which resources are just sufficient to provide a satisfactory life for all, Rawls's principles of Democratic Equality and those I have presented as the social safety net yield roughly the same distribution. While Rawls's principles look for the best possible position for the worst-off and find the satisfactory minimum, the social safety net looks for the worst-off group which can be brought up to the satisfactory material minimum and finds the worst-off group in society.

\section{Diagram 3: More than sufficient res}
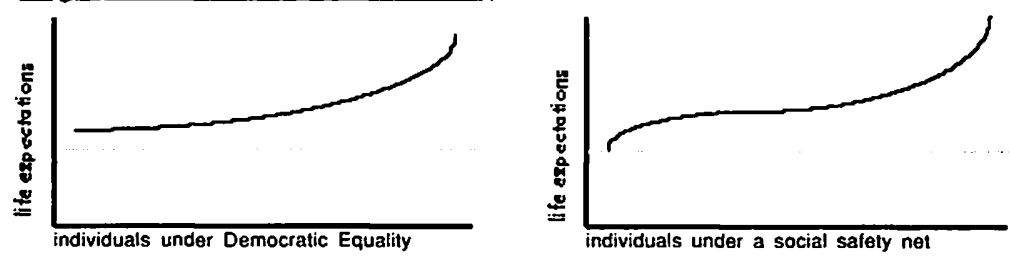

When there are more resources than necessary to raise all members of society to a satisfactory standard of living, no specific distribution or pattern can be predicted for the social safety net. Thus, the diagram on the right is somewhat arbitrary-in theory, any distribution with all members of society above the minimum 
bar is acceptable. However, on the whole we might expect greater inequalities than under Rawls's principles, owing to the uneven distribution of natural talents.

Even given this analysis and our understanding of the original position, it is still not immediately clear how the parties will choose one conception of justice over another. Rawls argues that parties in the original position should reason from the position of the worstoff in society. If this is so, then the parties would have reason to prefer Democratic Equality over the social safety net, because in the two cases in which the competing conceptions differ (that is, in cases of less than and more than sufficient abundance), the worstoff are better off under Rawls's principles than under those I have presented. But why should the parties in the original position consider only the position of the least advantaged? It seems almost foolish for the parties to make a choice that will affect the entire basic structure of society by solely considering the interests of one group.

Rawls argues that the parties will reason from the position of the worst-off because, in the original position, rational parties will adopt the maximin rule. However, I believe that a closer examination of the original position and Rawls's assumptions about the motivation of the parties will reveal a more attractive alternative to both the maximin rule and Rawls's principles.

\section{The Satisfactory Minimum: An Alternative to the Maximin Rule}

Rawls argues that his two principles of justice represent the maximin solution to the choice of principles under uncertainty. When applying the maximin rule to several alternative sets of possible outcomes, individuals assume that the least favorable outcome in each alternative set of possible outcomes will obtain, and then choose the course of action which provides for the best result in these unhappy circumstances. For instance, if I were to apply the maximin rule to a choice about the basic structure of society in which my place in society is uncertain, then I would choose as if my worst enemy were in charge of assigning me that place. Or, to give a more abstract example, let us consider the table below. 
Diagram 4: The Maximin Rule

\begin{tabular}{|c|c|c|c|c|}
\hline & Decisions & cl & $\underline{c 2}$ & $\underline{c 3}$ \\
\hline let $\mathrm{d} 1-\mathrm{d} 3$ represent the possible & dI & 0 & 3 & 12 \\
\hline choices available to the chooser & $d 2$ & 4 & 7 & 9 \\
\hline and let $c /-c 3$ represent the possible & $d 3$ & 5 & 6 & 8 \\
\hline
\end{tabular}

outcomes which may obtain

Given the possible choices $d l-d 3$, the maximin solution is $d 3$, as the worst possible outcome under $d 3$ (the value 5 ) is better than the worst possible outcome under $d I$ (the value 0 ) and $d 2$ (the value 4).

If it were indeed rational for the parties to use this rule, then parties would consider only the position of the worst-off when ranking alternative conceptions of justice, and it seems quite plausible that they would prefer Rawls's principles to a social safety net, or indeed to any alternative principle of justice. But why is it plausible to argue, as Rawls does, that parties in the original position would rank competing conceptions of justice according to this unusually conservative rule? Rawls admits that the maximin rule is not a rule which is fit for all decisions. However, he argues, the maximin rule is well suited to choices in situations marked by certain special features. In particular, Rawls singles out three features of choice situations which make the maximin rule attractive:

(1) Knowledge of the likelihoods of the different possible outcomes of the decision is impossible.

(2) Parties making the decision care very little for possible gains above the minimum that they can assure themselves of by using the maximin rule.

(3) Non-maximin options have possible outcomes that the decision-maker can hardly accept. [p. 154]

Rawls argues that the original position realizes all three of these features; indeed, he writes that "the original position has been 
defined so that it is a situation in which the maximin rule applies." [p. 155] But do these features really apply to the original position?

Consider feature (2), that parties making the decision care very little for possible gains above the minimum that they can assure themselves of by using the maximin rule. This appears to imply that Rawls's two principles, as the maximin solution to the choice problem in the original position, can guarantee to all of the members of society a satisfactory standard of living. Yet we have already discussed the possibility that some societies will be unable to provide a satisfactory standard of living to all. Because the choice of principles should not depend on the contingent circumstances of a particular society, there is no legitimate way to rule out this possibility, and therefore no such guarantee can be made from the original position for any conception of justice, including Rawls's own.

In such a society (as Diagram I illustrates), the minimum that the parties can assure themselves of by using the maximin rule is, as it turns out, still unsatisfactory. In these circumstances, feature (2) is not realized: the parties making the decision may care very much about possible gains above the minimum that they can assure themselves of by using the maximin rule; specifically, those gains which will elevate them from that position to one allowing a reasonably satisfactory standard of living. (Looking back to the table in Diagram 4, it is as though the parties require a score of at least 6.5 to achieve a satisfactory material minimum. In such cases, it would no longer be true that the parties care very little for gains above the maximin guarantee of 5.)

I believe that Rawls's error is to assume that the minimum promised by the two principles of justice will be a satisfactory minimum. For instance, he writes that

if we can maintain that these principles provide a workable theory of social justice, and that they are compatible with reasonable demands of efficiency, then this conception guarantees a satisfactory minimum. There may be, on reflection, little reason for trying to do better. [p. 156] 
And again, when discussing the risks of choosing utilitarianism, Rawls argues that

\begin{abstract}
Since the parties have the alternative of the two principles of justice, they can in large part sidestep the uncertainties of the original position. They can guarantee the protection of their liberties and a reasonably satisfactory standard of life as the conditions of their society permit. [p. 169]
\end{abstract}

To be sure, Rawls is at liberty to argue that the two principles of justice will lead an impoverished society to develop in ways such that all members of society will eventually be guaranteed a satisfactory minimum material standard of living. Nonetheless, this does not allow the parties in the original position to discount the possibility that they may find themselves in an impoverished society before such changes have taken effect. Indeed, given what we already know about the conservative nature of the parties, it seems likely that they will consider this possible situation to be of greater importance than situations of abundance. Thus, no such guarantees can be made from the original position, and there is, unfortunately, no way to sidestep its uncertainties.

Because the maximum minimum and the satisfactory minimum of a given choice situation need not be the same, parties presented with the table in Diagram 4 would not necessarily be inclined to choose the maximin solution $d 3$ merely because it guarantees that they can do no worse than a value of 5 , as a value of 5 may still be unsatisfactory. Imagine that the table in Diagram 4 represents a situation in which only values of 6.5 or higher are acceptable. Parties in such a situation would be better off neglecting $d 3$ for choice $d 2$, in which they have a better chance of securing for themselves a satisfactory value. But how can we say this in light of stipulation (1), that there is no way of assessing probabilities? There is in fact a limited way of assessing probabilities. The parties may presume that the probability of outcome $c 2$ is greater than zero (otherwise the exercise is meaningless), and that choice $d 2$ yields an acceptable value (the value 7) under outcome $c 2$ while choice $d 3$ yields an unacceptable value (the value 6); also, there are no possible 
outcomes in which choice $d 3$ yields an acceptable value while choice $d 2$ does not. Thus, a person choosing $d 2$ does have a higher probability of securing an acceptable score than does a person choosing d3. Similarly, as demonstrated in Diagram 1, in situations of scarcity the social safety net provides a satisfactory standard of living to some who would not enjoy a satisfactory standard of living under the alternative.

What, then, can we say about feature (3), that non-maximin solutions have possible outcomes that the decision maker can hardly accept? While it is true that the social safety net includes the possibility of unsatisfactory outcomes, so do Rawls's principles, and so would any principles given a society in which there is not enough to provide a good life for all. To be sure, Rawls's special conception of justice avoids the atrocities sometimes imagined by critics of utilitarianism-the priority of liberty ensures that none will be enslaved or coerced. However, the social safety net which I have endorsed also incorporates the priority of liberty and the same guarantee. But no principles of justice can guarantee a satisfactory standard of living from the original position which Rawls sets forth.

And what of cases in which a society has more than enough to provide a satisfactory standard of living to all its of members? First, we should keep in mind that, given the conservative nature of the parties, they would be less worried about situations of abundance than about situations of scarcity. Nonetheless, let us consider the table in Diagram 4 yet again, this time imagining that scores of 3.5 and higher are acceptable. This is enough to rule out some possible choices (such as choice $d I$ ), but would not provide rational grounds for choosing between $d 2$ and $d 3$. There seems to me to be no good reason for parties to refuse to gamble in such a case, as long as they are still guaranteed a good life.

Therefore, I suggest an alternative to the maximin rule: that in situations of uncertainty of outcomes, parties should attempt to determine which outcomes are satisfactory, and then choose whichever course of action presents the best chance of achieving one of the satisfactory outcomes. Using a principle similar to this one, parties in the original position would choose principles which guaranteed them the best chance of living a satisfactory life-that is, principles under which as many people as is possible have the 
primary goods necessary to pursue satisfactory lives. As I think the diagrams in the previous section make clear, this is best achieved by a system including a social safety net.

\section{Further Considerations}

While the original position is a useful device for making vivid the restrictions which seem reasonable to impose on arguments for or against competing conceptions of justice, it still cannot resolve disputes regarding what restrictions are reasonable and which are not. Put another way, we might say that different ideas about what are the reasonable restrictions to place on arguments for principles of justice would lead to different conceptions of the original position. As many of Rawls's critics have pointed out, the original position which Rawls sets forth already reflects, to some degree, Rawls's own conception of justice and the relevant considerations which lead to a conception of justice. Therefore, it is argued, the original position which Rawls describes is biased toward the selection of his principles.

This seems reasonable-for instance, if parties in the original position had knowledge of their natural abilities and talents, then the more talented would probably not agree to the difference principle. However, I would like to point out that the social safety net may not be as vulnerable to this objection. For instance, the talented would still not know exactly how events will play out, and they might see good reason to guarantee themselves a minimum (or their best chance at a minimum) against risk while still leaving open the possibility of great gains if their talents are recognized. Even a Wilt Chamberlain might wish to insure himself against injury or social conditions in which his talents are not appreciated (for instance, if the only lucrative spectator sport in a society were horse racing). Thus, I think that support for this more moderate conception of justice can be generated at almost any level of abstraction from actual contingencies. All we need to do is ask, "What if things hadn't turned out the way they did?" to feel the attraction of a safety net to protect us from the unforeseeable. 


\section{$\underline{\text { Rawlsian Counter-objections }}$}

Given the argument laid out here, what might a committed Rawlsian argue in support of the difference principle? As we have seen, there are two general socioeconomic situations on which these principles of justice can be contrasted and contested: situations of scarcity and situations of superabundance. With regard to situations of scarcity, a Rawlsian line of argument might press on the notion of a satisfactory minimum as the criterion of judgment. A Rawlsian might contend that the argument which I have presented so far seems to artificially reduce a spectrum of outcomes down to two possibilities: satisfactory and unsatisfactory. Even if we accept that we can draw a line between satisfactory allotments of primary goods and unsatisfactory ones (which, it must be admitted, is a provocative claim in its own right), we should note that there are degrees of "unsatisfactoriness." From the position of the worst-off, the difference between the social safety net and the difference principle might be the difference between extreme poverty and somewhat milder poverty.

I suspect that this argument may boil down to a matter of priorities. After all, both the maximin rule and the satisfactory minimum rule may be considered conservative: one guarantees the greatest allotment of goods that can be guaranteed, while the other guarantees the greatest likelihood of a satisfactory allotment of goods. I, for one, find the notion of a satisfactory minimum more compelling. There also seems to be support for this general idea in the broader political culture: when we speak, for instance, of a decent standard of living or more generally of a good life. What I think we find troubling about the presence of poverty in our society is not that there are inequalities which exist which are not to the advantage of the impoverished, but instead that individuals must unnecessarily endure standards of living which are inhumane and living conditions which are unacceptable.

With regard to situations of superabundance, a Rawlsian might press on the possibility of extreme inequalities. Consider a society in which the vast majority lives at the bare minimum for a satisfactory existence, while a small handful enjoys extreme wealth and privilege, far in excess of their fellow citizens. Such a society 
is, at least hypothetically, acceptable under a social safety net, but is there nothing in such extreme inequality to arouse our sense of injustice? Shouldn't we be concerned with the possibility that the social safety net might allow for the creation of a hyper-privileged class lording over an underclass which subsists at the minimum?

While I consider such a situation unlikely, the probability of the scenario introduced is somewhat besides the point: the point of the objection is that if this scenario came about, we would have reason to consider it unjust. However, I am unconvinced that this extreme situation, at least in the negative terms in which it has been described, would be allowed under the social safety net. I believe that what offends our sense of justice is the suggestion of the kind of persisting inequality which exists in our society, in which the possessors of wealth and privilege pass on these advantages to their children in the form of superior education and fuller opportunity, and in which the offspring of the disadvantaged are excluded from crucial opportunities for success and advancement. This is the kind of situation suggested by the talk of class distinctions arising within our hypothetical society: a small and wealthy privileged class enjoying advantages over a larger underclass.

While the social safety net is more tolerant of inequalities than is the difference principle-the social safety net does not require that inequalities be justified with reference to the life prospects of the least advantaged-it would still not allow for these persisting, class inequalities. This is because the conception of justice which I have advanced retains the requirement of fair equality of opportunity. I consider it a central requirement of social justice that each individual have equal access to the avenues of personal growth and enhancement, and I do not believe that this equality of access is threatened by the set of principles which I have described. Therefore, to the extent that a society organized under the proposed conception of justice could have a class structure, it would have to be a fluid and therefore, I think, less objectionable class structure. 